\title{
Phylogenetic Analysis of Lichen-Forming Fungi Rhizoplaca Zopf from China Based on ITS Data and Morphology
}

\author{
Xiao-Ling Zheng ${ }^{\mathrm{a}}$, Hong-Mei Sheng ${ }^{\mathrm{a}}$, and Li-Zhe $\mathrm{An}^{\mathrm{a}, \mathrm{b}, *}$ \\ a Key Laboratory of Arid and Grassland Agroecology of Ministry of Education, \\ School of Life Sciences, Lanzhou University, Lanzhou 730000, P. R. China. \\ Fax: +869318912561. E-mail: lizhean@lzu.edu.cn \\ b Cold and Arid Regions Environmental and Engineering Research Institute, \\ Chinese Academy of Sciences, Lanzhou 730000, P. R. China \\ * Author for correspondence and reprint requests \\ Z. Naturforsch. 62 c, 757-764 (2007); received November 23, 2006/February 7, 2007
}

A molecular phylogenetic analysis of Rhizoplaca melanophthalma, Rhizoplaca chrysoleuca, Rhizoplaca peltata and Rhizoplaca haydenii is presented based on the nuclear ribosomal internal transcribed spacer (ITS) regions and morphology. Rhizoplaca species were collected at 3400-3900 m in Tianshan Mountains, Xinjiang province, China. Rhizoplaca haydenii is reported for the first time in China. Maximum parsimony (MP) analysis of ITS sequences obtained from Tianshan Mountains samples and GenBank reveals that the evolution relationship of Rhizoplaca melanophthalma and Rhizoplaca chrysoleuca is closer to each other than to Rhizoplaca peltata, and Rhizoplaca haydenii showed closer relatedness to Rhizoplaca melanophthalma. When the four species groups from Tianshan Mountains were analyzed alone through the neighbour-joining (NJ) and minimum evolution method, we obtained the same result. The morphology analysis of Rhizoplaca Zopf which reveals the pruinose discs and apothecial discs of species did not show convincing evidences to prove phylogenetic relationship among Rhizoplaca species. In our study, the result further proved that Rhizoplaca should be rejected as a genus separate from Lecanora.

Key words: Rhizoplaca Zopf, Phylogeny, ITS

\section{Introduction}

The lichen has a widely geographical distribution in the world. It is a symbiotic association which is constituted by fungi and algae or cyanobacteria. The biological character of lichen is reflection of the essentiality of fungi within the symbiotic association. Therefore, lichen has been named lichen-forming fungi (Hawksworth and Hill, 1984) or lichenized fungi (Wei, 1982).

Rhizoplaca Zopf belongs to the division lichenforming Ascomycetes and family Lecanoraceae. It comprises more than nine species distributed throughout the world, only six of them are found in China. There are R. chrysoleuca (Sm.) Zopf, $R$. fumida X. Q. Gao, R. huashanensis Wei, R. melanophthalma (Ram. in Lam. \& DC.) Leuckert et Poelt, $R$. subdiscrepans (Nyl.) and R. peltata (Ram.) Leuckert et Poelt including two variations v. peltata and v. regalis (H. Magn.) Wei (Wei, 1991). According to the study of Wei and Wei (2005), $R$. fumida may be treated as one of the chemotypes within $R$. chrysoleuca.

Rhizoplaca Zopf was separated from the genus Squamaria DC. based on its single central rhizoid
(Zopf, 1905). Afterward, Poelt (1958) advanced that Rhizoplaca Zopf is a genus separate from Lecanora. Whereas, Ryan and Nash (1997) doubted the relationship between Rhizoplaca Zopf and Lecanora and suggested to do some further investigation. Arup and Grube (2000) adapted that Rhizoplaca Zopf is not a genus separate from Lecanora and may not be a monophyletic genus. Cansaran et al. (2006) also supported this result. At present, researchers focus on the phylogenetic relationship among Rhizoplaca Zopf and other correlated genera (Arup and Grube, 2000), however, studies on phylogenetic relationships among these species are very limited.

Originally, lichenologists used thallus structure and secondary metabolism to study the phylogenetic relationship of the lichen (Sundin and Tehler, 1998; Crespo et al., 1999). However, there is not distinct difference of the characters within genera or between species and no further support for genera that are characterized mainly by their thallus morphology. In addition, chemical similarity or difference is not a reliable evidence of systematic relationships because chemistry is varied in many 
species and sporadically shared by different groups (Leuckert et al., 1977; Wei, 1984; Ryan and Nash, 1997; Arup and Grube, 2000; Wei and Wei, 2005; Zhou et al., 2006). With the improvement of molecular technology, more and more lichenologists began to deeply reveal the phylogenetic relationship of the lichen and identify the cryptic genus within morphologically homogeneous groups using modern molecular techniques. The internal transcribed spacer regions of nuclear ribosomal DNA have been proved to be very useful in analyzing the genetic relationship among species. Internal transcribed spacer (ITS) sequences information has been one of the primary criteria in investigating the relationship at the specific level.

The aim of our study was: 1) to investigate the phylogenetic relationship among Rhizoplaca species by using ITS sequence analysis; 2) through analyzing morphological characters, to research whether pruinose discs and apothecial discs can be used to test the phylogenetic relationship among Rhizoplaca species.

\section{Materials and Methods}

\section{Growth conditions and sample collection}

The lichens in our study were collected from an ice-free cirque $\left(43^{\circ} 05^{\prime} \mathrm{N}, 86^{\circ} 49^{\prime} \mathrm{E}\right.$, with an altitude of 3400-3900 m) near the No. 1 glacier in the source area of Urumqi river in Tianshan Mountains, Xinjiang province, China. The annual average temperature is lower than $5^{\circ} \mathrm{C}$ in daytime and $-4^{\circ} \mathrm{C}$ at night. The temperature also undergoes a big fluctuation from nearly 4 to $-10^{\circ} \mathrm{C}$ during the favourable growth season from June to September. All samples were carefully cleaned with distilled water to remove possible epiphytic contaminants and then air-dried at room temperature. Finally, all dried samples were conserved at $-20^{\circ} \mathrm{C}$.

\section{DNA isolation, PCR and sequencing}

Total DNA was obtained from dried lichen using the modified CTAB (cetyl-trimethyl ammonium bromide) method (Murtagh et al., 1999). The extraction procedure was as follows: Lichen herbarium materials were ground under liquid nitrogen and $0.1 \mathrm{~g}$ suspended in $600 \mu \mathrm{l}$ extraction buffer (50 mu Tris [tris(hydroxymethyl) amino methane]$\mathrm{HCl}$ (pH 8.0), $50 \mathrm{~mm}$ EDTA; Biodee, Beijing, China) and $100 \mu \mathrm{l}$ of $10 \%$ SDS (Biodee). The solution was incubated in water at $65^{\circ} \mathrm{C}$ for $3-5 \mathrm{~h}$.
$80 \mu \mathrm{l}$ high concentration $\mathrm{CTAB} / \mathrm{NaCl}$ (Biodee) and $100 \mu \mathrm{l} \mathrm{NaCl}(5 \mathrm{M})$ were added to the solution. Then the solution was incubated at $65^{\circ} \mathrm{C}$ for $5 \mathrm{~min}$ to further eliminate protein. One volume of equilibrated phenol/chloroform/isoamylalcohol [25:24:1 $(\mathrm{v} / \mathrm{v} / \mathrm{v})]$ (Biodee) was added and mixed thoroughly by inversion. Then, samples were centrifuged at $12,000 \times g$ for 5 min (MIKRO 22R, Hettich, Tuttlingen, Germany). If precipitated protein was still observed at the aqueous/organic interface, extra washes were performed as necessary. 0.54 Volume of isopropanol was added and incubated at $4{ }^{\circ} \mathrm{C}$ for $2 \mathrm{~h}$ to precipitate DNA. Following centrifugation $(14,000 \times g, 5 \mathrm{~min})$, the pellet was washed twice with $80 \%$ ethanol, dried in air and re-suspended in $50 \mu \mathrm{l}$ of TE buffer [10 mM Tris-HCI, 1 mm EDTA ( $\mathrm{pH}$ 8.0)]. Total DNA was examined for quantity and quality on an ethidium-bromidestained 1\% agarose gel (Yito Enterprise Comp. Ltd., Shanghai, China) and stored at $-20^{\circ} \mathrm{C}$.

DNA reaction mixture was performed in $25 \mu \mathrm{l}$ using 10-50 ng genomic DNA as template, $2.5 \mu \mathrm{l}$ dNTP (Takara, Ootsu-shi, Shiga-ken, Japan), $2.5 \mu \mathrm{l}$ $10 \times$ PCR buffer (Takara), $1.5 \mu 110 \mathrm{~mm}$ primers and $0.3 \mathrm{U}$ Dynazyme Taq polymerase (Takara). ITS4 (TCCTCCGCTTATTGATATGC) (White $e t$ al., 1990) and ITS1-F (CTTGGTCATTTAGAGGAAGTAA) (Gardes and Bruns, 1993) were used to amplify the ITS sequence. Polymerase chain reaction (PCR) amplification was executed with the following program: initial denaturation at $95^{\circ} \mathrm{C}$ for $4 \mathrm{~min}$, and subsequently a 35 cycles reaction with annealing at $50{ }^{\circ} \mathrm{C}$ for $1 \mathrm{~min}$, extension at $72{ }^{\circ} \mathrm{C}$ for $1 \mathrm{~min}$, denaturation at $94{ }^{\circ} \mathrm{C}$ for $1 \mathrm{~min}$ and final extension at $72^{\circ} \mathrm{C}$ for $5 \mathrm{~min}$. The PCR products were visualized on $1 \%$ agarose gel as a band of approx. 500 or $800 \mathrm{bp}$. Then the products were cleaned using the purification kit (Takara) following the manufacturer's instructions. Sequencing was accomplished using an automated sequencer ABI3730 (ABI, Foster City, USA).

\section{Sequence alignment and phylogenetic analysis}

Our sequences were aligned using Clustal X1.83 (Thompson et al., 1994). All parameters were default values of the software. Maximum parsimony (MP) analysis was determined using PAUP*4b4a (Swofford, 1999) with the following settings: the matrix was subjected to 10 replicates of random sequence additions using heuristic searches, tree bisection and reconnection (TBR) branch swap- 
ping. Gaps were treated as "missing". One tree was held at each step during stepwise addition. Confidence limits for branches of the trees were performed by bootstrap analysis with 1,000 replications.

Neighbour-joining (NJ) and minimum evolution method analysis were carried out using MEGA3.1 (Kumar et al., 2004) with the following settings: two-parameter method was used to calculate the genetic distance matrix and construct the neighbour-joining tree and minimum evolution analysis. Gaps and missing data were completely deleted. Confidence limits for branches of the trees were performed by bootstrap analysis with 1,000 replications. Parmelia sulcata and Protoparmelia badia were used as outgroups.

\section{Results}

In our study, we obtained ITS sequence data for twenty-five samples of Rhizoplaca genus from Tianshan Mountains. There are ten $R$. melanophthalma (EF095278, EF095279, EF095280, EF095282, EF095283, EF095285, EF095286, EF095287, EF095290, EF095297), eight $R$. peltata (EF095275, EF095281, EF095284, EF095289, EF095291, EF095295, EF095296, EF101891), six R. chrysoleuca (EF095274, EF095276, EF095277, EF095293, EF095294, EF095298) and one R. haydenii (EF095292). All sequences have been depos- ited in GenBank. The species, localities and the GenBank accession numbers of twenty ITS data of Rhizoplaca Zopf obtained from GenBank are shown in Table I.

Rooted with Parmelia sulcata (AF410840) and Protoparmelia badia (AF070023) as outgroups our analysis is justified through the results of molecular investigation in the relationship among species of the Rhizoplaca genus (Arup and Grube, 2000; Zhou et al., 2006).

One hundred maximum parsimony trees with 761 parsimony-informative characters [consistency index $(\mathrm{CI})=0.5608$; retention index $(\mathrm{RI})=0.6319]$ were found by a heuristic search, one of the trees is shown in Fig. 1. The trees are similar to each other in topologic, with only slight re-arrangements in the group containing $R$. melanophthalma.

When the phylogenetic tree is examined, R. peltata group from Tianshan Mountains and three different samples of $R$. peltata (AY509802, AY509803, AF159936) from GenBank appear on the same branch. Lecanora dispersoareolate (AF070016) and $R$. peltata (AY509802) form a sister branch with $100 \%$ support within the $R$. peltata group. Also $R$. melanophthalma and $R$. chrysoleuca locate in two other branches of the tree that form a sister group with the same species from different countries by $71 \%$ bootstrap. R. haydenii (Tuck.) Follm (AF159937) appears within

Table I. Species, GenBank accession numbers and localities of twenty ITS data of Rhizoplaca Zopf obtained from GenBank.

\begin{tabular}{lcc}
\hline Species & GenBank accession No. & Origin \\
\hline Rhizoplaca chrysoleuca & AY303147 & China \\
Rhizoplaca chrysoleuca & AY509800 & China \\
Rhizoplaca chrysoleuca & AY304153 & China \\
Rhizoplaca chrysoleuca & AY509798 & China \\
Rhizoplaca chrysoleuca & AY509792 & China \\
Rhizoplaca chrysoleuca & AF159942 & Idaho, USA \\
Rhizoplaca chrysoleuca & AF159940 & Kazakhstan \\
Rhizoplaca chrysoleuca & AF159924 \\
Rhizoplaca peltata & AY509803 & Arizona, USA \\
Rhizoplaca peltata & AF159936 & China \\
Rhizoplaca peltata & AY509802 & China \\
Rhizoplaca melanophthalma & AY509791 & China \\
Rhizoplaca melanophthalma & AF159929 \\
Rhizoplaca melanophthalma & AF159935 \\
Rhizoplaca haydenii & AF159937 & Arizona, USA \\
Rhizoplaca idahoensis Rosentreter ined. & AF159943 & Austria \\
Rhizoplaca cylindrica Ryan ined. & AF159941 & Austria \\
Lecanora dispersoareolate & AF070016 & Idaho, USA \\
Parmelia sulcata & AF410840 & Idaho, USA \\
Protoparmelia badia & AF070023 & Turkey \\
\hline
\end{tabular}




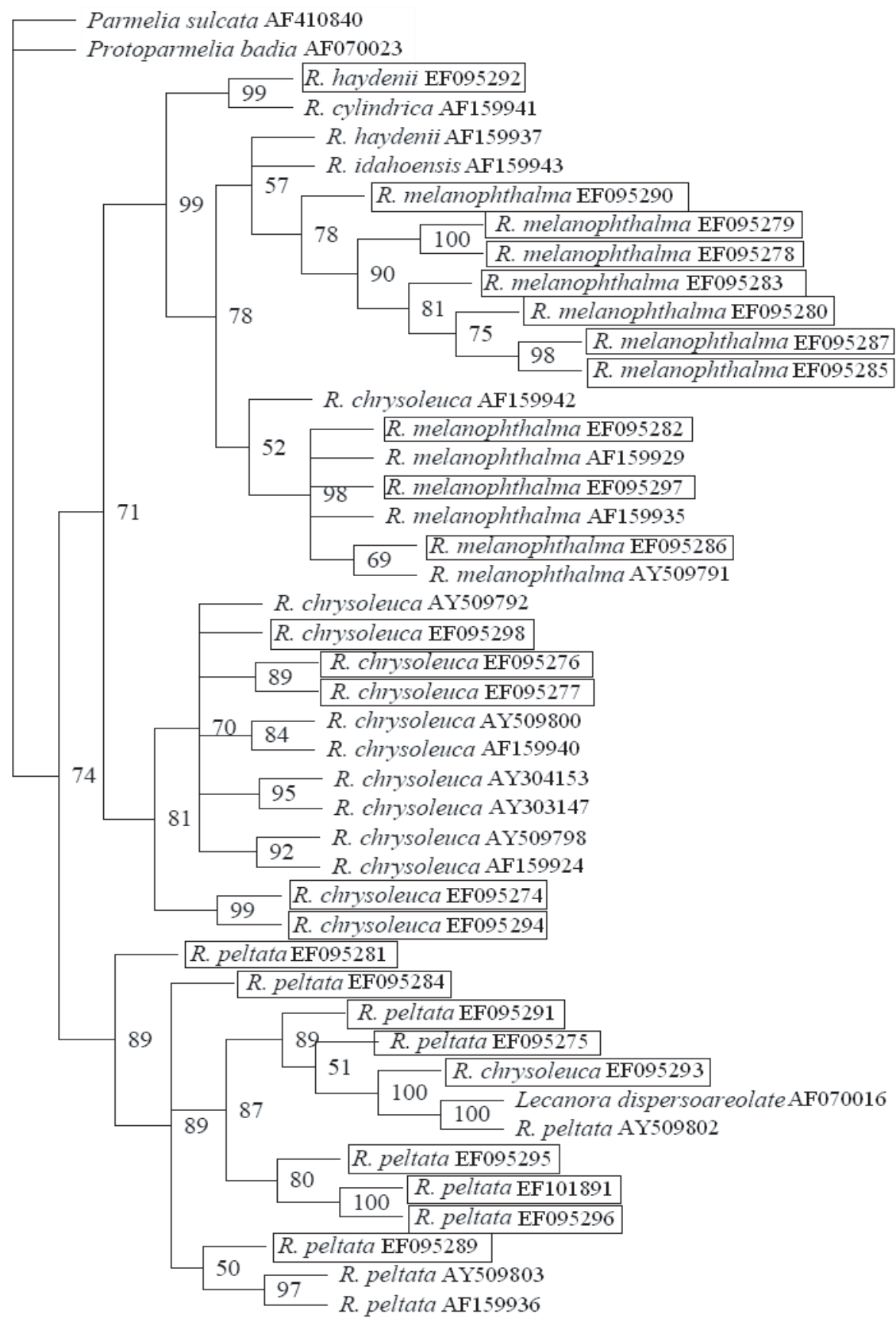

Fig. 1. Maximum parsimony analysis inferred from ITS region sequences of Rhizoplaca species from Tianshan Mountains and GenBank. Bootstrap percentages greater than $50 \%$. Species group from Tianshan Mountains is located in the frames.

the $R$. melanophthalma group, and $R$. haydenii (EF095292) together with the $R$. melanophthalma group form a sister branch with $99 \%$ support.
Similar results are also obtained from neighbour-joining and minimum evolution analyses that included a species group (that are found in the 


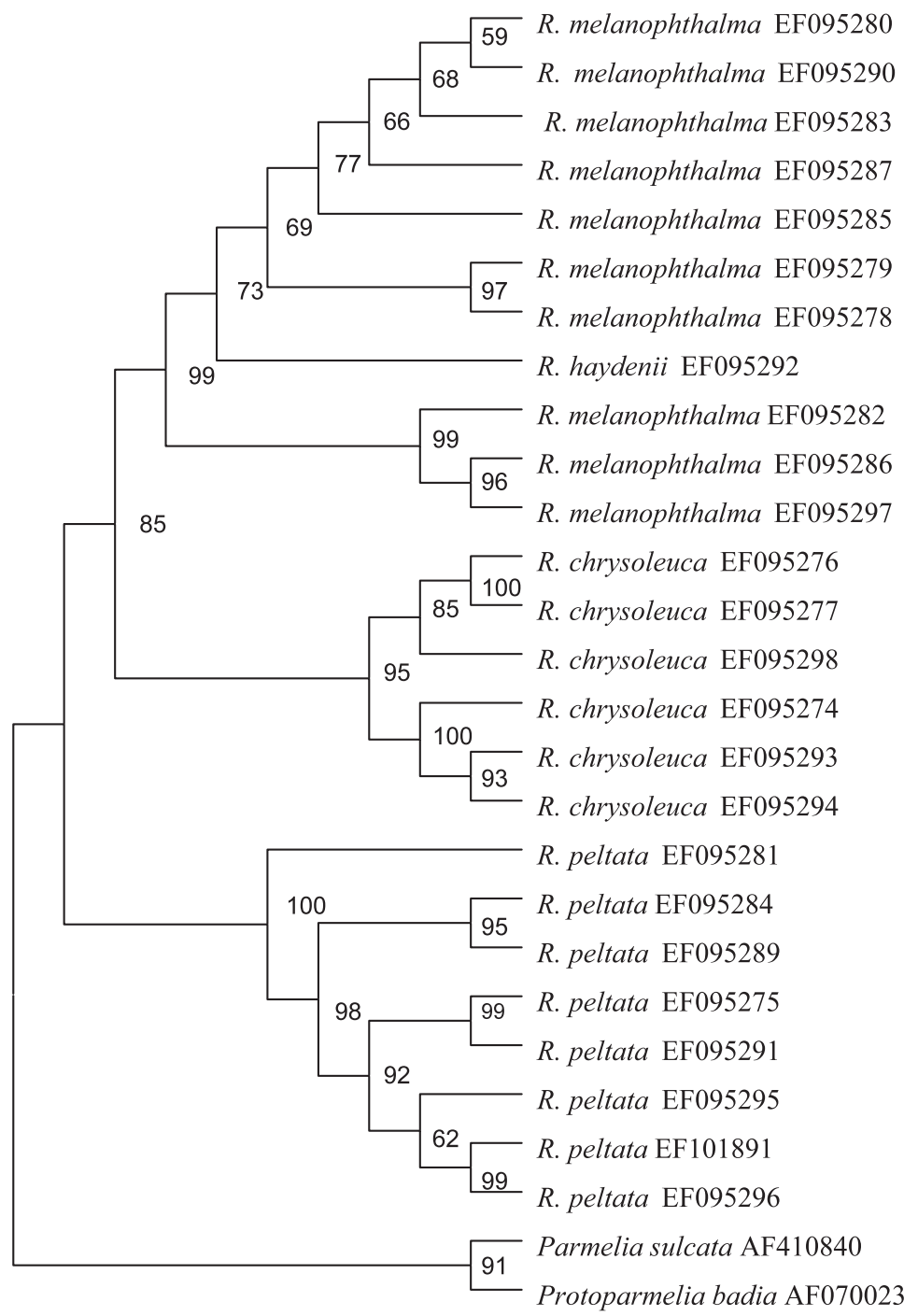

Fig. 2. Neighbour joining analysis inferred from ITS region sequences of Rhizoplaca species from Tianshan Mountains.

first analysis) from Tianshan Mountains in China. $R$. peltata, $R$. melanophthalma and $R$. chrysoleuca groups appear on three different branches. $R$. melanophthalma and $R$. chrysoleuca form a sister branch (with bootstrap value of $85 \%$ in $\mathrm{NJ}$ and $86 \%$ in the minimum evolution analysis). R. haydenii (EF095292) emerges as a sister group to the $R$. melanophthalma group within $R$. melanophthalma. Phylogenetic trees of neighbour-joining and minimum evolution analyses are corresponding to each other, with only slight re-arrangements in the group containing $R$. melanophthalma, and are shown in Fig. 2 and Fig. 3.

\section{Discussion}

\section{Phylogenetic analysis}

In phylogenetic trees, $R$. melanophthalma emerges as a sister group to $R$. chrysoleuca (with bootstrap values of $71 \%$ in the MP, $85 \%$ in the NJ and $86 \%$ in the minimum evolution analysis), whereas $R$. peltata appears on a different branch of the trees (with bootstrap values of $89 \%$ in the MP, $100 \%$ in the NJ and $100 \%$ in the minimum evolution analysis). The same branching pattern was also found in other papers, such as Zhou et al. (2006) and Arup and Grube (2000). It indicates 


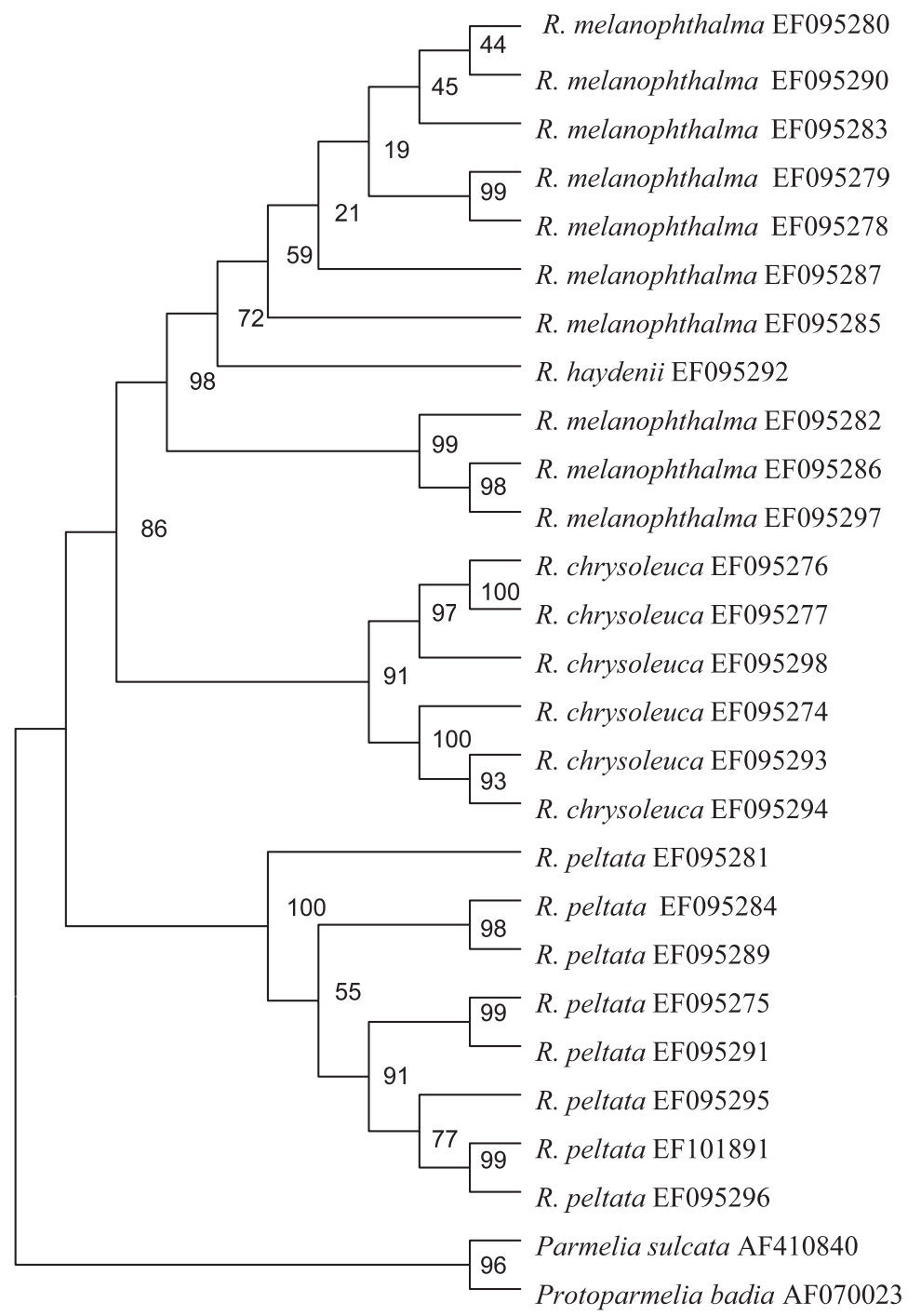

Fig. 3. Analysis by minimum evolution according to the data obtained by ITS region sequences from Tianshan Mountains.

that $R$. melanophthalma and $R$. chrysoleuca are phylogenetically closer than $R$. peltata, while Cansaran et al. (2006) maintained that $R$. melanophthalma and $R$. peltata were phylogenetically closer to each other than $R$. chrysoleuca. In their neighbour-joining tree, the topology of $R$. peltata and $R$. melanophthalma was supported only by $28 \%$ bootstrap values. And the topology structures of maximum parsimony and minimum evolution analyses weren't consistent with the neighbourjoining tree. However, they were the same as ours.

In addition, we also studied the phylogenetic relationship of $R$. haydenii and the other three spe- cies of the Rhizoplaca genus. $R$. haydenii is reported for the first time in China. The thallus morphology has no distinct difference from that shown by Arup and Grube (2000). Thalli of $R$. haydenii is an almost globose structure formed by the folding of broader and flatter lobes. In our phylogenetic analysis, $R$. haydenii and $R$. melanophthalma form a sister branch within the $R$. melanophthalma group, which is supported by the bootstrap value $99 \%$ in MP, $73 \%$ in NJ and $72 \%$ in minimum evolution. Therefore, we think that $R$. haydenii is closer related to $R$. melanophthalma than others. The same conclusion can be found in 
Zhou et al.'s neighbour-joining tree (with bootstrap value of 99\%) and Arup and Grube's maximum parsimony and maximum-likelihood analyses (with bootstrap value of $100 \%$ and $99 \%$ ).

In maximum parsimony analysis, Lecanora dispersoareolate (AF070016) appears within the $R$. peltata group, a position strongly supported by a bootstrap value of $100 \%$. This result further proves that Rhizoplaca should be rejected as a genus separate from Lecanora (Arup and Grube, 2000).

\section{Morphology analysis}

Cansaran et al. (2006) maintained that $R$. melanophthalma and $R$. peltata were phylogenetically closer to each other than $R$. chrysoleuca was also based on morphological evidence. They found that $R$. chrysoleuca differed from $R$. peltata and $R$. melanophthalma by having pruinoses, orange apothecial discs, however, the apothecial discs were yellowish brown and not pruinose in $R$. peltata, yellow-brown to greenish or black and pruinose in $R$. melanophthalma. They observed only three samples, one $R$. melanophthalma, one $R$. peltata and one $R$. chrysoleuca. The conclusion is not enough universal. In our research, ten $R$. melanophthalma, eight $R$. peltata and six $R$. chrysoleuca

Arup U. and Grube M. (2000), Is Rhizoplaca (Lecanorales, lichenized Ascomycota) a monophyletic genus? Can. J. Bot. 78, 318-327.

Cansaran D., Aras S., Kandemir I., and Halıcı M. G. (2006), Phylogenetic relations of Rhizoplaca Zopf from Anatolia inferred from ITS sequence data. Z. Naturforsch. 61c, 405-412.

Crespo A., Gavilan R., Elix J. A., and Gutierrez G. (1999), A comparison of morphological, chemical and molecular characters in some parmelioid genera. Lichenologist 31, 451-460.

Gardes M. and Bruns T. D. (1993), ITS primers with enhanced specifity for basidiomycetes - application to the identification of mycorrhizae and rusts. Mol. Ecol. 2, 113-118.

Hawksworth D. L. and Hill D. J. (1984), The LichenForming Fungi. Blackie \& Son, Ltd, Glasgow, Scotland.

Kumar S., Tamura K., and Nei M. (2004), MEGA 3. Integrated software for molecular evolutionary genetics analysis and sequence alignment. Brief Bioinform. 5, $150-163$

Leuckert C., Schmitz K. E., and Feige G. B. (1977), Zur Chemotaxonomie der eurasischen Arten der Flechtengattung Rhizoplaca. Nova Hedwigia 28, 71-129. samples were examined. We noticed that $R$. chrysoleuca samples have green (EF095277) and brown (EF095276) apothecial discs except for orange (EF095298). The apothecial discs are all brown in $R$. peltata, and all greenish or black in $R$. melanophthalma. We didn't find pruinose in any samples during our study. Therefore, we think there are no convincing evidences to support the phylogenetic relationship among Rhizoplaca species by apothecial discs and pruinose of species.

Based on our research, we induce three conclusions as follows: 1) Rhizoplaca melanophthalma and Rhizoplaca chrysoleuca are phylogenetically closer to each other than Rhizoplaca peltata;2) the phylogenetic relationship of Rhizoplaca haydenii and Rhizoplaca melanophthalma is closer than of Rhizoplaca peltata and Rhizoplaca chrysoleuca; 3) apothecial discs and pruinose of species can not be selected to prove a phylogenetic relationship among Rhizoplaca species. Further work is in process, phylogenetic relationship of more species of Rhizoplaca Zopf will be researched.

\section{Acknowledgements}

We wish to thank Yang Zhong, Shou-Yu Guo, A. Abbas and Xiao-Li Jiang for assistance. The project was supported by the National Natural Science Foundation of China (90302010, 30625008).
Murtagh G. J., Dyer P. S., Mcclure P. C., and Crittenden P. D. (1999), Use of randomly amplified polymorphic DNA markers as a tool to study variation in lichenforming fungi. Lichenologist 31, 257-267.

Poelt J. (1958), Die lobaten Arten der Flechtengattung Lecanora Ach in der Holarktis. Mitt. Bot. Staatssamml. Muench. 2, 411-573.

Ryan B. D. and Nash T. H. (1997), Systematics of Lecanora subgenus Placodium (lichenizied Ascomycotina) in North America: an overview with keys. Nova Hedwigia 64, 111-127.

Sundin R. and Tehler A. (1998), Phylogenetic studies of the genus Arthonia. Lichenologist 30, 381-413.

Swofford D. L. (1999), Phylogenetic analysis using parsimony (*and other methods). Version 4. 0. Sinauer Associates, Sunderland, Mass.

Thompson J. D., Higgins D. G., and Gibson T. J. (1994), CLUSTAL W: improving the sensitivity of progressive multiple sequence alignment through sequence weighting, position specific gap penalties and weight matrix choice. Nucleic Acids Res. 22, 4673-4680.

Wei J. C. (1982), Medicine Lichen in China. Science Publ. Company, Beijing.

Wei J. C. (1984), A preliminary study of lichen genus Rhizoplaca from China. Acta Mycol. Sin. 3, 207-213. 
Wei J. C. (1991), A Checklist of Lichens in China. Wanguo Science Publishing Company, Beijing.

Wei X. L. and Wei J. C. (2005), A study on delimitation of Rhizoplaca chrysoleuca group based on comprehensive data. Mycosystema 24, 24-28.

White T. J., Bruns T. D., Lee S., and Taylor J. (1990), Amplification and direct sequencing of fungal ribosomal RNA genes for phylogenetics. In: PCR Protocols
(Innis M. A., Gelfand D. H., Sninsky J. J., and White T. J., eds.). Academic Press, San Diego, pp. 315-322.

Zhou O. M., Guo S. Y., Huang M. R., and Wei J. C. (2006), A study of the genetic variability of Rhizoplaca chrysoleuca using DNA sequences and secondary metabolic substances. Mycologia 98, 57-67.

Zopf W. (1905), Zur Kenntnis der Flechtenstoffe. Ann. Chem. 340, 276-309. 